\title{
PEMANFAATAN PELAYANAN PERSALINAN PADA FASILITAS KESEHATAN BERDASARKAN KELAS IBU HAMILDI PUSKESMAS HILA
}

\section{UTILIZATION OF BIRTH SERVICES AT HEALTH FACILITIES BASED ON CLASS OF PREGNANT WOMEN AT HILA HEALTH CENTER}

\author{
Rahma Badiu ', A. Ummu Salmah², Andi Mardiah Tahir ${ }^{3}$ \\ ${ }^{1}$ Dinas Kesehatan Provinsi Maluku \\ ${ }^{2}$ Departemen Kesehatan Reproduksi dan Keluarga, Fakultas Kesehatan Masyarakat, \\ UNHAS \\ ${ }^{3}$ Departemen Biomedik, Fakultas Kedokteran, UNHAS
}

\begin{abstract}
*Alamat Korespondensi :Rahma Badiu, Fakultas Kesehatan Masyarakat Universitas Hasanuddin J1. Perintis Kemerdekaan Azizah Residensi Blok A1 No.7, 085243017117, Email: $\underline{\text { rbadiu74@gmail.com }}$
\end{abstract}

\begin{abstract}
ABSTRAK
Inisiasi Menyusu Dini (IMD) adalah bayi diberi kesempatan memulai menyusu sendiri segera setelah lahir/dini, dengan membiarkan kontak kulit bayi dengan kulit ibu setidaknya satu jam atau lebih, sampai menyusu pertama selesai. Praktek IMD di Indonesia kurang dari 1 jam setelah bayi lahir hanya $34.5 \%$. Kurangnya pengetahuan dari orang tua sehingga IMD masih jarang dipraktekkan. Penelitian ini bertujuan untuk mengetahui pengaruh edukasi IMD terhadap pengetahuan dan sikap ibu hamil tentang IMD di wilayah kerja Puskesmas Palangloe Kabupaten Gowa. Jenis penelitian dengan metode quasi eksperiment dengan rancanganthe randomized pretest-posttest contol group design. Populasi dalam penelitian ini adalah seluruh ibu hamil yang berada di wilayah kerja puskesmas sebanyak $60 \mathrm{ibu}$ hamil pada bulan Januari-April 20017. Penarikan sampel menggunakan metode total sampling $60 \mathrm{ibu}$ hamil. Pengumpulan data dilakukan dengan menggunakan kuesioner. Uji statistik yang digunakan Mann Whitney, Wilcoxon dan Paired t Test. Hasil penelitian menunjukkan ada perbedaan kelompok intervensi dengan kelompok kontrol sebelum dan sesudah intervensi IMD dengan $\mathrm{p}<0,05$ dan ada pengaruh edukasi terhadap pengetahuan dan sikap ibu tentang IMD dengan $p<0,05$ (pengetahuan kelompok intervensi $\mathrm{p}=0,000$, pengetahuan kelompok kontrol $\mathrm{p}=0,000$; sikap kelompok intervensi $\mathrm{p}=0,000$ dan sikap kelompok kontrol $\mathrm{p}=0,000$ ). Terdapat peningkatan pengetahuan dan sikap ibu hamil mengenai IMD setelahdilakukan edukasi (penyuluhan)
\end{abstract}

Kata Kunci :IMD, sikap, pengetahuan

\section{ABSTRACT}

Early Breastfeeding Initiation (EBI) isthe baby given the opportunity to start their ownnursing immediately after birth / early, by letting the baby skin contact with the skin's motherat least one hour or more, until the first feeding is completed. However, lack of knowledge ofparents so that the IMD is still rarely practiced. This study aims to determine the effect of educational EBI on knowledge and attitude of pregnant women about EBI in the work area of Puskesmas Palangloe Gowa District. Type of research with quasi experiment method with the randomized pretest-posttest contol group design. The population in this study were all pregnant women in the work area of puskesmas as much as 60 pregnant women in January-April 20017. Sampling using total sampling method 60 pregnant women. The data were collected by using questionnaires. Statistic test used by Mann Whitney, Wilcoxon and Paired t Test. The results showed that there was a difference of the intervention group with the control group before and after the EBI intervention with $p<0.05$ and there was an effect of education on knowledge and attitude about EBI with $p<0,05$ (knowledge of intervention group $p=0,000,=0,000$, intervention group attitude $p=0,000$ and attitude of control group $p=0,000$ ). There were improved of knowledge level and attitude towards EBI on pregnant woman before and after counseling

Keywords:EBI, attitude, knowledge 


\section{PENDAHULUAN}

AKI masih menjadi masalah kesehatan di seluruh dunia. World Health Organization (WHO) memperkirakan terdapat 216 kematian ibu setiap 100.000 kelahiran hidup, 99\% kematian ibu terjadi di negara berkembang mencapai 239/100.000 kelahiran hidup, 20 kali lebih tinggi dibandingkan negara maju. Kematian ibu di Indonesia sebesar 126 setiap 100.000 kelahiran hidup pada tahun 2015, tertinggi di Negara-negara ASEAN (WHO, 2015).

Hasil Survei Penduduk Antar Sensus (SUPAS) pada tahun 2015AKI mengalami penurunan menjadi 305 kematian ibu per 100.000 kelahiran hidup. AKI di Provinsi Maluku sebesar 237 per 100.000 pada tahun 2015 (Dinkes Provinsi Maluku, 2016) sedangkan di Kabupaten Maluku Tengah jumlah AKI tahun 2013 adalah 11 kasus, pada 2014 jumlah menurun menjadi turun menjadi 10 dan pada tahun 2015 masih terdapat 10 kasus kematian. Sedangkan angka persalinan pada fasilitas kesehatan Puskesmas Hila tahun 2016 sebesar 49,09\%(Dinkes Maluku Tengah, 2016).

Kematian ibu pada umumnya terjadi masa kehamilan, persalinan dan nifas. $90 \%$ kematian ibu terjadi pada masa saat persalinan dan segera setelah persalinan. Faktor utama penyebab kematian ibu disebabkan oleh penyebab langsung $(77,2 \%)$ seperti perdarahan $(37 \%)$, infeksi (22\%) dan pre eklampsia (14\%) dan penyebab tidak langsung (penyakit kronis dan penyebab lainnya) yaitu sebesar 22,8 $\%$ (Kemenkes RI, 2015a).

Tingginya kasus kematian ibu juga diidentifikasi pula sebagai akibat tidak lansung yang mempersulit proses penanganan kedaruratan kehamilan, persalinan dan nifas yang dikenal dengan tiga terlambat yaitu terlambat mengenal tanda bahaya dan mengambil keputusan, terlambat mencapai fasilitas kesehatan dan terlambat mendapat penanganan kegawatdaruratan yang memadai (Kemenkes, 2015b).
Salah satu upaya yang telah dilakukan pemerintah dalam upaya penurunan AKI dan AKB adalah dengan membentuk kelas ibu hamil. Kelas ibu hamil merupakan salah satu kegiatan penting dalam meningkatkan penggunaan buku KIA di masyarakat sebagai upaya pembelajaran ibu, suami dan keluarga melalui kegiatan belajar bersama. Kelas ibu hamil bertujuan meningkatkan pengetahuan, mengubah sikap dan perilaku ibu agar memahami tentang pemeriksaan kehamilan, persalinan aman, nifas, bayi sehat, pencegahan penyakit fisik dan jiwa, gangguan gizi dan komplikasi kehamilan, persalinan dan nifas, perawatan bayi baru lahir agar tumbuh kembang optimal. Indikator keberhasilan program kelas ibu hamil adalah adanya peningkatan persentasi persalinan yang ditolong oleh tenaga kesehatan yang terampil pada fasilitas kesehatan (Kemenkes, 2015b).

Membangun kasadaran ibu hamil untuk memanfaatkan persalinan pada fasilitas kesehatan selain motivasi dari ibu juga memperlukan dukungan sosial. Dukungan sosial yang ada mengacu pada kenyamanan, perhatian, penghargaan, atau bantuan yang diberikan suami, keluarga maupun dari petugas kesehatan (Sarafino \& Smith, 2014). Penelitian yang dilakukan oleh Nurlinda (2014), menemukan bahwa dukungan suami/ keluarga mempengaruhi ibu dalam pemilhan persalinan pada fasilitas kesehatan.

Penelitian yang dilakukan oleh Fatimahdkk., (2014), di Kecamatan Jatinegara Jakarta Timur menunjukan bahwa ibu hamil yang mendapat dukungan dari tenaga kesehatan mampu mengambil keputusan untuk memilih persalinan pada fasilitas kesehatan. Penelitian ini bertujuan untuk menganalisis pemanfaatan pelayanan persalinan pada fasilitas kesehatan berdasarkan kelas ibu hamil di Puskesmas Hila Kabupaten Maluku Tengah Tahun 2017. 


\section{BAHAN DAN METODE}

\section{Lokasi dan Jenis Penelitian}

Penelitian ini dilaksanakan di

Puskesmas Hila Kabupaten Maluku

Tengah. Jenis penelitian ini adalah penelitian observasional analitik dengan rancangan cross sectional yaitu melakukan pengamatan pada variabel bebas (independent) dengan variabel tergantung (dependent) dilakukan dalam waktu yang sama (Sugiyono, 2013).

\section{Populasi dan sampel}

Populasi dalam penelitian ini adalah semua ibu bersalin yang mempunyai bayi usia 0-6 bulan di wilayah kerja Puskesmas Hila Kabupaten Maluku Tengah tahun 2017.Sampel pada penelitian ini adalah semua ibu bersalin yang pernah mengikuti kelas ibu sebanyak 120 orangdengan menggunakan teknik stratifiet proporsional random sampling.

\section{Pengumpulan data}

Pengumpulan data dalam penelitian ini dilakukan dengan menggunakan alat bantu kuesioner.

Tabel 1. Hubungan Kelas Ibu Hamil dan Usia dengan Pemanfaatan Layanan Persalinan di Puskesmas Hila Kabupaten Maluku TengahTahun 2017

\begin{tabular}{|c|c|c|c|c|c|c|c|}
\hline \multirow{4}{*}{ Kelas Ibu Hamil } & \multicolumn{6}{|c|}{ Pemanfaatan Layanan Persalinan } & \multirow{4}{*}{$P$} \\
\hline & \multicolumn{4}{|c|}{ di Fasilitas Kesehatan } & \multirow{2}{*}{\multicolumn{2}{|c|}{ Jumlah }} & \\
\hline & \multicolumn{2}{|c|}{$\mathrm{Ya}$} & \multicolumn{2}{|c|}{ Tidak } & & & \\
\hline & $\mathrm{n}$ & $\%$ & $\mathrm{~N}$ & $\%$ & $\mathrm{n}$ & $\%$ & \\
\hline Aktif & 28 & 53.8 & 24 & 46.2 & 52 & 100 & \\
\hline Tidak Aktif & 20 & 29.4 & 48 & 70.6 & 68 & 100 & 0.012 \\
\hline Total & 48 & 39.1 & 78 & 60.9 & 128 & 100 & \\
\hline
\end{tabular}

\section{Sumber: Data Primer, 2017}

Tabel 2. menunjukan bahwa respondenaktif mengikuti kelas ibu hamil yang memanfaatkan persalinan di fasilitas kesehatan usia berisiko ( $<20 \&>35$ tahun) $70.6 \%$, paritas berisiko $66.7 \%$ sedangkan responden yang tidak aktif kelas ibu hamil usia tidak berisiko $71.4 \%$ dan paritas berisko $81,8 \%$ tidak memanfaatkan persalinan di fasilitas kesehatan. Berdasarkanhasil uji statistik menunjukan hubungan Usia $(p=0,164)$, Paritas $(\mathrm{p}=0.631)$ pada kelompok responden yang aktif mengikuti kelas ibu hamil, sedangkan pada kelompok responden tidak aktif kelas ibu hamil Usia

\section{Analisis data}

Data dianalisis dengan menggunakan program SPSS dengan distribusi frekuensi, uji chi square dan regresi logistik berganda.

\section{HASIL PENELITIAN}

Tabel 1 menunjukkan bahwa sebagian besar responden yang aktif mengikuti kelas ibu hamil yang memanfaatkan layanan persalian di fasilitas kesehatan sebesar 53,8\% dibandingkan dengan yang tidak aktif mengikuti kelas ibu hamil hanya 29,4\% yang memanfaatkan layanan kesehatan untuk bersalin. Berdasarkan hasil uji statistik diperoleh nilai $\mathrm{p}=0,012$ pada $\alpha=0,05$. Karena nilai $p(0,012)<0,05$ hal ini berarti terdapat hubungan yang signifikan antara kelas ibu hamil dengan pemanfaatan layanan persalinan pada fasilitas kesehatan. 
pada responden yang tidak aktif berpengetahuan baik $46.7 \%$ dan yang pengetahuannya kurang $87.0 \%$ tidak memanfaatkan persalinan di fasilitas kesehatan Berdasarkan hasil uji statistik hubungan pengetahuan diperoleh nilai $p=0,030$ pada $\alpha=0,05$. Karena nilai $p$ $(0,030)<0,05$ yang artinya bahwa terdapat hubungan yang signifikan antara pengetahuan dengan pemanfaatan layanan persalinan pada responden yang aktif mengikuti kelas ibu hamil. Hasil uji statistic pada responden yang tidak aktif mengikuti kelas ibu hamil di peroleh nilai $\mathrm{p}=0.069>0.05$ berarti tidak terdapat hubungan pengetahuan dengan pemanfaatan persalinan di fasilitas kesehatan pada responden yang tidak aktif kelas ibu hamil.

Responden yang aktif mengikuti kelas ibu hamil mempunyai sikap Positif 61,7\%dan negatif (0\%) memanfaatkan pelayanan persalinan di fasilitas kesehatan. Sedangkan responden yang tidak aktif mengikuti kelas ibu hamil sikapnya positi $38.3 \%$ dan sikapnya sifatnya negatif $(9.5 \%)$ memanfaatkan layanan persalinan di fasilitas kesehatan. Berdasarkan hasil uji statistik diperoleh nilai $p \quad(0,039)<0,05$ pada responden yang aktif mengikuti kelas ibu hamildan pada responden yang tidak aktif kelas ibu hamil diperoleh nilai $p=0,034$ pada $\alpha=0,05$. Karena nilai $p<0,05$ yang artinya bahwa ada hubungan yang signifikan antara sikap dengan pemanfaatan layanan persalinan di fasilitas kesehatan pada responden yang aktif mengikuti kelas ibu hamil maupun yang tidak aktif mengikuti kelas ibu hamil.

Responden yang aktif mengikuti kelas ibu hamil mempunyai sikap Positif $61,7 \%$ dan negatif $(0 \%)$ memanfaatkan pelayanan persalinan di fasilitas kesehatan. Sedangkan responden yang tidak aktif mengikuti kelas ibu hamil sikapnya positi $38.3 \%$ dan sikapnya sifatnya negatif $(9.5 \%)$ memanfaatkan layanan persalinan di fasilitas kesehatan. Berdasarkan hasil uji statistik diperoleh nilai $p \quad(0,039)<0,05$ pada responden yang aktif mengikuti kelas ibu hamil dan pada responden yang tidak aktif kelas ibu hamil diperoleh nilai $\mathrm{p}=0,034$ pada $\alpha=0,05$. Karena nilai $\mathrm{p}<0,05$ yang artinya bahwa ada hubungan yang signifikan antara sikap dengan pemanfaatan layanan persalinan di fasilitas kesehatan pada responden yang aktif mengikuti kelas ibu hamil maupun yang tidak aktif mengikuti kelas ibu hamil.

Tabel 2. Hubungan Usia dan Paritasdengan pemanfaatan perasalinan di fasilitas Kesehatan Berdasarkan Kelas ibu Hamil di Puskesmas Hila Kabupaen Maluku Tengah Tahun 2017

\begin{tabular}{|c|c|c|c|c|c|c|c|c|}
\hline \multirow{4}{*}{$\begin{array}{l}\text { Kelas Ibu } \\
\text { Hamil }\end{array}$} & \multirow{4}{*}{ Variabel } & \multicolumn{4}{|c|}{ Pemanfaatan Layanan } & \multirow{3}{*}{\multicolumn{2}{|c|}{ Jumlah }} & \multirow{4}{*}{$\boldsymbol{P}$} \\
\hline & & \multicolumn{4}{|c|}{$\begin{array}{c}\text { Persalinan di Fasilitas } \\
\text { Kesehatan }\end{array}$} & & & \\
\hline & & \multicolumn{2}{|c|}{ Ya } & \multicolumn{2}{|c|}{ Tidak } & & & \\
\hline & & $\mathbf{N}$ & $\%$ & $\mathbf{n}$ & $\%$ & $\mathbf{N}$ & $\%$ & \\
\hline \multirow{3}{*}{ Aktif } & Usia & & & & & & & \multirow{3}{*}{0,164} \\
\hline & Berisiko & 12 & 70,6 & 5 & 29,4 & 17 & 100,0 & \\
\hline & Tidak Berisiko & 16 & 45,7 & 19 & 54,3 & 35 & 100,0 & \\
\hline \multirow{2}{*}{ Tidak Aktif } & Berisiko & 6 & 31,6 & 13 & 68,4 & 19 & 100,0 & \multirow{2}{*}{0,100} \\
\hline & Tidak berisiko & 14 & 28,6 & 35 & 71,4 & 49 & 100,0 & \\
\hline \multirow{3}{*}{ Aktif } & Paritas & & & & & & & \multirow{3}{*}{0.631} \\
\hline & Tidak Berisiko & 22 & 51.2 & 21 & 48.8 & 43 & 100 & \\
\hline & Berisiko & 6 & 66.7 & 3 & 33.3 & 9 & 100 & \\
\hline \multirow{2}{*}{ Tidak Aktif } & Tidak berisiko & 18 & 31.6 & 39 & 68.4 & 57 & 100 & \multirow{2}{*}{0.595} \\
\hline & Berisiko & 2 & 18.2 & 9 & 81.8 & 11 & 100 & \\
\hline
\end{tabular}

Sumber: Data Primer, 2017 
Tabel 3. Hubungan Penegtahuan dan Sikap dengan pemanfaatan perasalinan di fasilitas Kesehatan Berdasarkan Kelas ibu Hamil di Puskesmas Hila Kabupaen Maluku Tengah Tahun 2017

\begin{tabular}{|c|c|c|c|c|c|c|c|c|}
\hline \multirow{3}{*}{$\begin{array}{c}\text { Kelas Ibu } \\
\text { Hamil }\end{array}$} & \multirow{3}{*}{ Variabel } & \multicolumn{4}{|c|}{$\begin{array}{c}\text { Pemanfaatan Layanan Persalinan } \\
\text { di Fasilitas Kesehatan }\end{array}$} & \multirow{2}{*}{\multicolumn{2}{|c|}{ Jumlah }} & \multirow{3}{*}{$p$} \\
\hline & & \multicolumn{2}{|c|}{ Ya } & \multicolumn{2}{|c|}{ Tidak } & & & \\
\hline & & $\mathbf{N}$ & $\%$ & $\mathbf{n}$ & $\%$ & $\mathbf{N}$ & $\%$ & \\
\hline & $\begin{array}{l}\text { Pengetahua } \\
\text { n }\end{array}$ & & & & & & & \\
\hline \multirow{4}{*}{ Aktif } & Baik & 27 & 61.4 & 17 & 38.6 & 44 & 100 & \multirow{4}{*}{0.03} \\
\hline & Cukup & 1 & 12.5 & 7 & 87.5 & 8 & 100 & \\
\hline & Kurang & 0 & 0 & 0 & 0 & 0 & 100 & \\
\hline & Baik & 7 & 46.7 & 8 & 53.3 & 15 & 100 & \\
\hline \multirow[t]{2}{*}{ Tidak Aktif } & Cukup & 10 & 33.3 & 20 & 66.7 & 30 & 100 & \multirow[t]{2}{*}{0.069} \\
\hline & Kurang & 3 & 13 & 20 & 87 & 23 & 100 & \\
\hline \multirow{3}{*}{ Aktif } & Sikap & & & & & & & \multirow{3}{*}{0.039} \\
\hline & Positif & 28 & 59.6 & 19 & 40.4 & 47 & 100 & \\
\hline & Negatif & 0 & 0 & 5 & 100 & 5 & 100 & \\
\hline \multirow{2}{*}{ Tidak Aktif } & Positif & 18 & 38.3 & 29 & 61.7 & 47 & 100 & \multirow{2}{*}{0.034} \\
\hline & Negatif & 2 & 9.5 & 19 & 90.5 & 21 & 100 & \\
\hline
\end{tabular}

Sumber: Data Primer, 2017

Tabel 4 menunjukan bahwa responden yang aktif mengikuti kelas ibu hamil menyatakan bahwa akses ke layanan mudah $60.0 \%$, petugas kesehatan mendukung $64,3 \%$, dan mendapat dukungan keluarga $77.1 \%$ memanfaatkan pelayanan persalinan di fasilitas kesehatan sedangkan pada responden yang tidak aktif mengikuti kelas ibu hamil menyatakan akses mudah 30.4\%., mendapat dukungan petugas kesehatan $48.6 \%$, dan dukungan keluarga $73.9 \%$ memanfaatkan pelayanan persalinan di fasiliras kesehatan Berdasarkan hasil uji statistik hubungan Akses diperoleh nilai $p=0,040<0.05$ pada kelompok responden yang aktif kelas ibu hamil dan responden yang tidak aktif $p=0.964$ pada $\alpha=0,05$. Karena nilai $\mathrm{p}(0,040)<0,05$ yang artinya bahwa terdapat hubungan yang signifikan antara akses ke layanan kesehatan dengan pemanfaatan pelayanan persalinan di fasilitas kesehatan pada responden yang aktif mengikuti kelas ibu hamil. Sedang pada responden yang tidak aktif nilai $p=0,964$ pada $\alpha=0,05$. Karena nilai $\mathrm{p}(0,964)>0,05$ yang artinya bahwa tidak terdapat hubungan yang signifikan antara akses layanan kesehatan dengan pemanfaatan layanan persalinan di fasilitas kesehatan pada responden yang tidak aktif mengikuti kelas ibu.

Hasil uji statistik hubungan dukungan tenaga kesehatan dan dukungann keluarga diperoleh nilai $\mathrm{p}=0,006$ pada responden yang aktif mengikuti kelas ibu hamil variabel dukungan tenaga kesehatan $(p=0,006)$, dukungan keluarga $(p=0.001)$ dan pada kelompok resonden yang tidak aktif kelas ibu hamil dukungan tenaga kesehatan $(\mathrm{p}=0.001)$, dukungan keluarga $(\mathrm{p}=0.000)$. Karena nilai $\mathrm{p}<0,05$ yang artinya bahwa terdapat hubungan yang signifikan antara dukungan petugas kesehatan dengan pemanfaatan layanan persalinan di fasilitas kesehatan baik pada responden yang mengikuti kelas ibu hamil maupun yang tidak aktif mengikuti kelas ibu hamil. 
Tabel 4. Hubungan Akses, Dukungan Tenaga Kesehatan dan dukungan keluarga dengan pemanfaatan perasalinan di fasilitas Kesehatan Berdasarkan Kelas ibu Hamil di Puskesmas Hila Kabupaen Maluku Tengah Tahun 2017

\begin{tabular}{|c|c|c|c|c|c|c|c|c|}
\hline \multirow{4}{*}{$\begin{array}{c}\text { Kelas Ibu } \\
\text { Ham } \\
\text { il }\end{array}$} & \multirow{4}{*}{ Variabel } & \multirow{2}{*}{\multicolumn{4}{|c|}{$\begin{array}{c}\text { Pemanfaatan Layanan } \\
\text { Persalinan di } \\
\text { Fasilitas Kesehatan } \\
\end{array}$}} & \multirow{2}{*}{\multicolumn{2}{|c|}{ Jumlah }} & \multirow{4}{*}{$p$} \\
\hline & & & & & & & & \\
\hline & & \multicolumn{2}{|c|}{ Ya } & \multicolumn{2}{|c|}{ Tidak } & \multirow[b]{2}{*}{$\mathbf{N}$} & \multirow[b]{2}{*}{$\%$} & \\
\hline & & $\mathbf{N}$ & $\%$ & $\mathbf{n}$ & $\%$ & & & \\
\hline \multirow{3}{*}{ Aktif } & Akses & & & & & & & \multirow{3}{*}{0.04} \\
\hline & Mudah & 27 & 60 & 18 & 40 & 45 & 100 & \\
\hline & Sulit & 1 & 14.3 & 6 & 85.7 & 6 & 100 & \\
\hline \multirow{2}{*}{ Tidak Aktif } & Mudah & 17 & 30.4 & 39 & 69.6 & 56 & 100 & \multirow{2}{*}{0.964} \\
\hline & Sulit & 1 & 12.5 & 7 & 87.5 & 8 & 100 & \\
\hline \multirow{3}{*}{ Aktif } & Dukunga Nakes & & & & & & & \multirow{3}{*}{0.006} \\
\hline & Mendukung & 27 & 64.3 & 15 & 35.7 & 42 & 100 & \\
\hline & Tidak Mendukung & 1 & 10 & 9 & 90 & 10 & 100 & \\
\hline \multirow{2}{*}{ Tidak Aktif } & Mendukung & 17 & 48.6 & 18 & 51.4 & 35 & 100 & \multirow{2}{*}{0.001} \\
\hline & Tidak Mendukung & 3 & 9.1 & 30 & 90.9 & 33 & 100 & \\
\hline \multicolumn{9}{|c|}{ Dukungan Keluarga } \\
\hline \multirow{2}{*}{ Aktif } & Mendukung & 27 & 77.1 & 8 & 22.9 & 35 & 100 & \multirow{2}{*}{0.001} \\
\hline & Tidak Mendukung & 1 & 5.9 & 16 & 94.1 & 17 & 100 & \\
\hline \multirow{2}{*}{ Tidak Aktif } & Mendukung & 17 & 73.9 & 6 & 26.1 & 23 & 100 & \multirow{2}{*}{0.000} \\
\hline & Tidak Mendukung & 3 & 6.7 & 42 & 96.2 & 45 & 100 & \\
\hline
\end{tabular}

Sumber: Data Primer, 2017

Tabel 5 menunjukan hasil analisis multivariat dari beberapa tahapan dengan metode backward yang mengeluarkan satu persatu variabel yang kurang memberi pengaruh mulai dari pengaruh terkecil. Hasil uji statistik dengan regresi logistik berganda dari tahapan terakhir (step 3) diperoleh variabel yang secara simultan berhubungan dengan pemanfaatan pelayanan persalinan di fasilitas kesehatan adalah Akses $\mathrm{p}=0,048$ $(\mathrm{W}=3,894)$ dan dukungan keluarga $\mathrm{p}=0,000(\mathrm{~W}=12,242)$. Sehingga diperoleh variabel yang paling berpengaruh dengan pemanfaatan layanan persalinan di Puskesmas Hila KabupatenMaluku Tengah Tahun 2017 adalah variabel Dukungan Keluarga.

Tabel 5. Hasil Analisis Uji Regresi Logistik Pemanfaatan Layanan Persalinan Di Puskesmas Hila Kabupaten Maluku Tengah Tahun 2017

\begin{tabular}{llrrrrr}
\hline Variabel & \multicolumn{1}{c}{ B } & Wald & df & Sig. & Exp(B) \\
\hline Step 1 $^{\text {a }}$ & Pengetahuan(1) & 2.339 & 2.603 & 1 & 0.107 & 10.372 \\
& Sikap(1) & 21.459 & 0 & 1 & 0.999 & $2.09 \mathrm{E}+09$ \\
Akese(1) & 2.908 & 4.539 & 1 & 0.033 & 18.323 \\
Duk_Petugas(1) & 1.012 & 0.336 & 1 & 0.562 & 2.75 \\
& Duk_Keluarga(1) & 3.742 & 8.717 & 1 & 0.003 & 42.177 \\
Constant & -2.202 & 12.448 & 1 & 50 & 0.111 \\
\hline
\end{tabular}




\begin{tabular}{llrrrrr}
\hline \hline Variabel & B & & Wald & df & Sig. & \multicolumn{2}{c}{$\operatorname{Exp}(\mathrm{B})$} \\
\hline Step 2 $^{\mathrm{a}}$ & Pengetahuan(1) & 2.275 & 2.462 & 1 & 0.117 & 9.729 \\
& Sikap(1) & 21.479 & 0 & 1 & 0.999 & $2.13 \mathrm{E}+09$ \\
& Akese(1) & 2.871 & 4.505 & 1 & 0.034 & 17.648 \\
& Duk_Keluarga(1) & 4.038 & 11.149 & 1 & 0.001 & 56.709 \\
& Constant & -2.151 & 12.408 & 1 & 43 & 0.116 \\
Step 3 $^{\text {a }}$ & Sikap(1) & 21.27 & 0 & 1 & 0.999 & $1.73 \mathrm{E}+09$ \\
& Akese(1) & 2.604 & 3.894 & 1 & 0.048 & 13.513 \\
& Duk_Keluarga(1) & 4.205 & 12.89 & 1 & 0.000 & 66.988 \\
& Constant & -1.878 & 12.242 & 1 & 12 & 0.153 \\
\hline
\end{tabular}

Sumber : Data Primer, 2017.

\section{PEMBAHASAN}

Penelitian ini menemukan bahwa ada hubungan mengikuti kelas ibu hamil dengan pemanfaatan persalinan pada fasilitas kesehatan. Responden yang aktif mengikuti kelas ibu hamil (minimal 3 kali) lebih banyak memanfaatkan fasilitas kesehatan untuk bersalin dibandingkan tidak aktif mengikuti kelas ibu hamil. Pengetahuan dan Akses berhubungan dengan pemanfaatan persalinan pada fasilitas kesehatan $(p=<0.05)$ pada kelompok yang aktif kelas ibu hamil, sedangkan pada kelompok tidak aktif kelas ibu hamil tidak ditemukan adanya hubungan pengetahuan dan akses dengan pemanfaatan persalinan pada fasilitas kesehatan. Sikap, Dukungan petugas kesehatan dan dukungan keluarga berhubungan dengan pemanfaatan persalinan pada fasilitas kesehatan dengan nilai $p=<0.05$ baik pada yang aktif kelas ibu hamil maupun tidak aktif kelas ibu hamil.

Kelas ibu hamil atau antenatal class merupakan suatu sarana untuk belajar bersama tentang kesehatan bagi ibu hamil. Kegiatan ini bertujuan untuk meningkatkan pengetahuan, merubah sikap dan perilaku sehingga ibu hamil mampu mempraktekkan kehidupan yang sehat, yang berkaitan dengan perawatan kehamilan, persalinan yang aman, masa nifas yang aman ibu selamat dan bayi sehat. Pelaksanaan kelas ibu hamil akan menjadikan ibu hamil mampu mengaplikasikan hal-hal yang telah diperoleh darikelas ibu hamil, sehingga bila terjadi penyulit atau komplikasi selama kehamilan dapat diketahui sedini mungkin dan dapat ditangani secara optimal. Ibu hamil yang aktif mengikuti kelas ibu hamil mempunyai pengetahaun tentang kesehatan ibu dan anak lebih baik, materi diberikan pada kelas ibu hamil secara bertahap dan berkesinambungan minimal 3 kali (Kemenkes RI 2015b).Penelitian yang dilakukan oleh Hutapea (2012), di Wilayah Kerja Puskesmas Cibungbulang Kecamatan Cibungbulang Kabupaten Bogor menemukan bahwa keikutsertaan kelas ibu hamil berhubungan dengan pemilihan penolong persalinan.Penelitian Weitzman A, (2016) di Peru menunjukan bahwa ibu hamil yang mengikuti pendidikan tentang kesehatan Ibu dan Anak secara rutin selama kehamilan mempunyai pengetahuan yang baik sebesar $80 \%$ dan meningkatkan probabilitas ibu hamil untuk menghadiri pemeriksaan kehamilan (antenatal care) serta pemanfaatan persalinan pada fasilitas kesehatan.Penelitian Brixval, et al (2016) di Denmark menunjukan bahwa Ibu hamil yang mengikuti pendidkan pada kelas ANC mempunyai sikap dan kepercayaan diri yang positif dalam menghadapi proses persalinan dan rujukan persalinan pada fasilitas kesehatan 
Perilaku ibu hamil ke fasilitas kesehatan untuk bersalin sangat ditentukan oleh kondisi lingkungan.Kecenderungan untuk tidak melakukan persalinan ke fasilitas kesehatan disebabkan karena aksesyang tidak terjangkau oleh ibu hamil menuju ke fasilitas kesehatan. Kondisi geografis yang tidak baik serta sulitnya transportasi menuju fasilitas kesehatan menyebabkan ibu hamil dan ibu nifas tidak bersalin ke fasilitas kesehatan.Hubungan positif antara jarak dengan pemanfaatan pelayanan kesehatan adalah makin jauh suatu pelayanan kesehatan makin segan mereka datang. Ada batas jarak tertentu sehingga orang masih mau bepergian untuk mencari dan memanfaatkan pelayanan kesehatan. Batas jarak ini pun dipengaruhi oleh jenis jalan, jenis kendaraan, waktu tempuh, kendaraan pribadi, berat ringan penyakit dan kemampuan membayar Hasil penelitian yang dilakukan oleh Kawakatsu et al., (2014), di Kenya menunjukkan bahwa kedekatan akses ke fasilitas kesehatan berhubungan dengan pemanfaatan persalinan pada fasilitas kesehatan. Penelitian oleh Jeinet (2015), di Puskesmas Makale Torajamenemukan bahwa ada hubungan keterjangkauan dengan pemanfaatan pelayanan pertolongan persalinan.

Dukungan tenaga kesehatan mempunyai hubungan yang signifikan dengan pemanfaatan persalinan difasilitas kesehatan $(p=<0.05)$ ibu hamil yang mendapat dukungan dari petugas kesehatan memanfaatkan pelayanan persalinan di fasilitas ksehatan sebaliknya yang mendapatkan informasi/tidak mendapat dukungan dari petugas kesehatan tidak memanfaatkan pelayanan di fasilitas kesehatan. Penelitian Fatimaf et al., (2014), tentang perencanaan persalinan pada ibu yang mengikuti kelas ibu hamil mendapatkan infotmasi dari orang yang tepat dan berkompoten, dukungan tenaga kesehatan terlihat berpengaruh positif terhadap pengambilan keputusan persalinan pada fasilitas kesehatan ( $\mathrm{p}=0.000)$. Penelitian Rochaya (2012), tentang hubungan kelas ibu hamil terhadap pemilihan penolong persalinan, ditemukan ada hubungan yang bermakna antara dukungan petugas kesehatan dengan pemilihan penolong persalinan.Penelitian Hutapea (2012), di wilayah kerja Puskesmas Cibungbulang Kecamatan Cibungbulang Kabupaten Bogor menemukan bahwa dukungan suami berhubungan dengan pemilihan penolong persalinan.

Dukungan keluarga mempunyai hubungan yang signifikan dengan pemanfaatan persalinan di fasilitas kesehatan $(\mathrm{p}=<0.05)$. Friedman, (2010)) menyatakan dukungan keluarga adalah sikap, tindakan dan penerimaan keluarga terhadap anggotanya. Anggota keluarga dipandang sebagai bagian yang tidak terpisahkan dalam lingkungan keluarga. Anggota keluarga memandang bahwa orang yang bersifat mendukung selalu siap memberikan pertolongan dan bantuan jika diperlukan.Bentuk dukungan keluarga dalam perawatan kesehatan adalah dukungan instrumental, dukungan penilaian, dukungan informasional, dan dukungan emosional (Friedman, 2010). Memutuskan bersalin atau tidak bersalin ibu hamil ke fasilitas kesehatan dipengaruhi oleh dirinya sendiri dan lingkungan sosialnya di mana dalam hal ini adalah orang tua, suami dan masyarakat.

Dukungan emosional adalah bentuk dukungan dimana keluarga sebagai tempat pemulihan yang aman dan damai untuk beristirahat dan membantu secara psikologis untuk menstabilkan emosi dam mengendalikan diri. Dukungan keluarga terutama dukungan emosional secara tidak langsung akan mempunyai manfaat emosional yang akan memberikan kekuatan pada diri seseorang.Dukungan emosional misalnya dengan memberikan perhatian dan dukungan, kedekatan dan kehangatan yang membuat pasien merasa dicintai dan disayangi, bersimpati dan empati terhadap persoalan yang dihadapi pasien, dan memberikan nasihat dan peringatan. Dukungan emosional yang kurang dapat menurunkan motivasi pasien 
untuk melakukan perawatan kesehatan. Sedangkan dukungan yang baik akan meningkatkan motivasi pasien untuk melakukan perawatan kesehatan dalam hal kepatuhan menjalankan pengobatan selama masa pasca melahirkan (Nainggolan dkk., 2013).

Adanya persepsi keluarga yang negatif mengenai persalinan ke fasilitas kesehatan menyebabkan ibu hamil tidak bersalin ke fasilitas kesehatan. Selain juga ada faktor penentu di luar kehendak ibu hamil yang juga memengaruhi keputusan untuk bersalin ke fasilitas kesehatan atau tidak, seperti: ibu melahirkan di luar waktu yang ditentukan sehingga tidak memungkinkan untuk dibawa ke fasilitas kesehatan serta ibu hamil yang berisiko tinggi saat persalinan karena mengalami perdarahan dan pre-eklamsi sehingga mengharuskan untuk bersalin ke fasilitas kesehatan (Notoatmodjo, 2014).Hasil diatas sejalan pula dengan peneltian yang Nurlinda (2014), menunjukan bahwa dukungan keluarga(suami dan orang tua) berpengaruh dalam pemilihan tempat bersalin.Penelitian Kawakatsu et al., (2014), di Kenyamenmeukan bahwa dukungan keluarga berupa dana berhubungan dengan pemanfaatan persalinan pada fasilitas kesehatan.

\section{KESIMPULAN DAN SARAN}

Penelitian menyimpulkan bahwa ada hubungan mengikuti kelas ibu hamil dengan pemanfaatan persalinan pada fasilitas kesehatan. Responden yang aktif mengikuti kelas ibu hamil lebih banyak memanfaatkan fasilitas kesehatan untuk bersalin dibandingkan tidak aktif mengikuti kelas ibu hamil. Pengetahuan dan Akses berhubungan dengan pemanfaatan persalinan pada fasilitas kesehatan pada kelompok yang aktif kelas ibu hamil, sedangkan pada kelompok tidak aktif kelas ibu hamil tidak ditemukan adanya hubungan pengetahuan dan akses dengan pemanfaatan persalinan pada fasilitas kesehatan. Dukungan petugas kesehatan dan dukungan keluarga berhubungan dengan pemanfaatan persalinan pada fasilitas kesehatan baik pada yang aktif kelas ibu hamil maupun tidak aktif kelas ibu hamil. Tidak terdapat hubungan yang bermakna antara usia dan paritas dengan pemanfaatan persalinan di fasilitas kesehatan baik pada kelompok yang aktif maupun yang tidak aktif mengikuti kelas ibu hamil. Penelitian ini menyarankan perlunya ibu hamil mendapat edukasi secara rutin untuk peningkatan kualitas kehamilan, agar ibu dapat menerapkan informasi yang diperoleh dari kelas ibu hamil untuk menjaga status gizi dan pertumbuhan janinnya, serta agar petugas kesehatan rutin memberikan edukasi melalui kelas ibu hamil untuk meningkatkan pengetahuan ibu tentang kehamilan dan persalinan yang aman dan dan keluarga memberi dukungan dalam bentuk informan dan dana agar ibu bersalin di fasilitas kesehatan.

\section{DAFTAR PUSTAKA}

Abigail Weitzman, (2017). The effects of Women's education on maternal health Evidence from Peru, Social Science \& Medicine (2017), doi: 10.1016/j.socscimed.2017.03.004. Brixva,et al. 2016. Antenatal Education in Small Classes may Increase Childbirth Selfefficacy: Resultsfrom a Danish randomised trial, Sexual \& Reproductive

Dinkes Provinsi Maluku, (2016) Profil Kesehatan Provinsi Maluku Tahun 2015

Dinkes Maluku Tengah. (2016). Profil Kesehatan Kabupaten Maluku Tengah Tahun 2016. Maluku Tengah

Friedman, M.M, Bowden, O dan Jones, M, 2010. Buku Ajar Kepeawatan Keluarga: Riset, Teori dan Praktik Edisi 5. EGC. Jakarta

Fatimah, Sugeng T, Aisyah. (2014). Determinan Pengambilan Keputusan Dalam Perencanaan Persalinan Pada Kelas Ibu Hamil. Poltekkes Kemenkes Jakarta III Vol. 2, Nomor 1, hlm : 37-43 
Hutapea, E. (2012). Faktor-Faktor Yang Berhubungan Dengan Pemilihan Penolong Persalinan Di Wilayah Kerja Puskesmas Cibungbulang Kecamatan Cibungbulang Kabupaten Bogor Jawa Barat Tahun 2012

Jeinet, M.T. (2015). Faktor Yang Berhubungan Dengan Pemanfaatan Pelayanan Pertolongan Persalinan Oleh Tenaga Kesehatan Di Wilayah Kerja Puskesmas Makale

Kawakatsu, Y., Sugishita, T., Oruenjo, K., Wakhule, S., Kibosia, K., \& Were, E. (2014). Determinants Of Health Facility Utilization For Childbirth In Rural Western Kenya: Cross-Sectional Study. BMC Pregnancy and Childbirth

Kemenkes Republik Indonesia. (2015a). Profil Kesehatan Indonesia Tahun 2014. Jakarta

Kemenkes Republik Indonesia. (2015b). Modul Pelatihan Fasilitator Kelas Ibu Hamil dan Kelas Ibu Balita. Jakarta

Notoatmodjo, S. (2014). Ilmu Perilaku Kesehatan. Jakarta : Rineka Cipta

Nurlinda, Suprianto S. (2014). Pengaruh Faktor Karakteristik, Psikologi dan Sosial terhadap pemilihan Persalinan pada Fasilitas
Kesehatan. Universitas Arlangga. Vol 2. No.4

Nainggolan O, Hapsari, Indrawati L. (2013).Pengaruh Akses ke Fasilitas Kesehatan terhadap Kelengkapan Imunisasi Baduta. (AnalisisRiskesdas

2013)Puslitbang Upaya Kesehatan Masyarakat, Kemenkes RI, Jl. Percetakan Negara No. 29, Jakarta 10560, Indonesia Media Litbangkes, Vol. 26 No. 1, Maret 2016, 15-28

Rochayah, S. (2012). Hubungan Kelas Ibu Hamil dengan Pemilihan Penolong Persalinan di Wilayah Puskesmas Bruno Kabupaten Purworejo Jawa Tengah Tahun 2012. Skripsi. Jakarta: Fakultas Kesehatan Universitas Indonesia

Sarafino, E.P. \& Smith, T. W. (2014). Health Psychology Biopsychological interaction (8th ed.). New York: Wiley

Sugiyono. (2013). Metode Penelitian Kuantitatif, Kualitatif dan $R \& D$. Bandung : Alfabeta

WHO. (2015). Trends in Maternal Mortality: 1990 to 2015, UNICEF, UNFPA, World Bank Group and the United Nations Population Division). Ganeva, Switzerland 